\title{
Further Studies on Amino Esters of Substituted Phenylcarbamic Acids
}

\author{
RICHARD DAHLBOM and ALFONSMISIORNY
}

Research Laboratories, AB Astra, Södertälje, Sweden

\begin{abstract}
The synthesis of some amino esters of 2,6-dimethylphenylcarbamic acid substituted in the para position with an amino group or substituted amino group is described. Two amino esters of 2-chloro-6-methylphenylcarbamic acid were also prepared. The new compounds have been tested for local anesthetic activity.
\end{abstract}

Tn a previous paper the synthesis of some esters and amides of 2,6-dimethyl

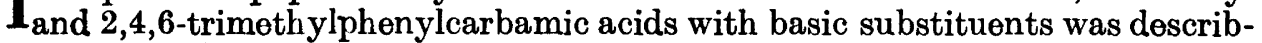
od ${ }^{1}$. As an extension of these investigations a number of related compounds of the following type were prepared, $\mathrm{R}$ being $\mathrm{H}, n-\mathrm{C}_{4} \mathrm{H}_{9}$ or an acyl group.<smiles>[R]Nc1cc(C)c(NC(=O)OCN([AlH2])[AlH2])c(C)c1</smiles>

The starting material for these syntheses was ethyl 2,6-dimethyl-4nitrophenylcarbamate (I) which could be preparod from 2,6-dimethyl-4nitroaniline and ethyl chloroformate. It could also be obtained in good yield by nitration of ethyl 2,6-dimethylphenylcarbamate. The smooth formation of the 4-nitro compound in this case is rather interesting since the nitration of 2,6-dimethylacetanilide and 2,6-dimethylformanilide mainly gives the 3-nitro derivatives ${ }^{2}$. As ethyl 2,6-dimethyl-4-nitrophenylcarbamate is easily hydrolysed to 2,6-dimethyl-4-nitroaniline in almost quantitative yield, this method opens a new satisfactory route to this amine in addition to the method devised by Wepster ${ }^{2}$. The different steps involved in the synthesis of the amino esters (V, VI) and their alkyl and acyl derivatives (VIII-XI) are shown in Fig. 1.

In addition, the $\beta$-diethylaminoethyl and $\beta$-piperidinoethyl esters of 2-chloro-6-methylphenylcarbamic acid were prepared (XIII, XIV). 


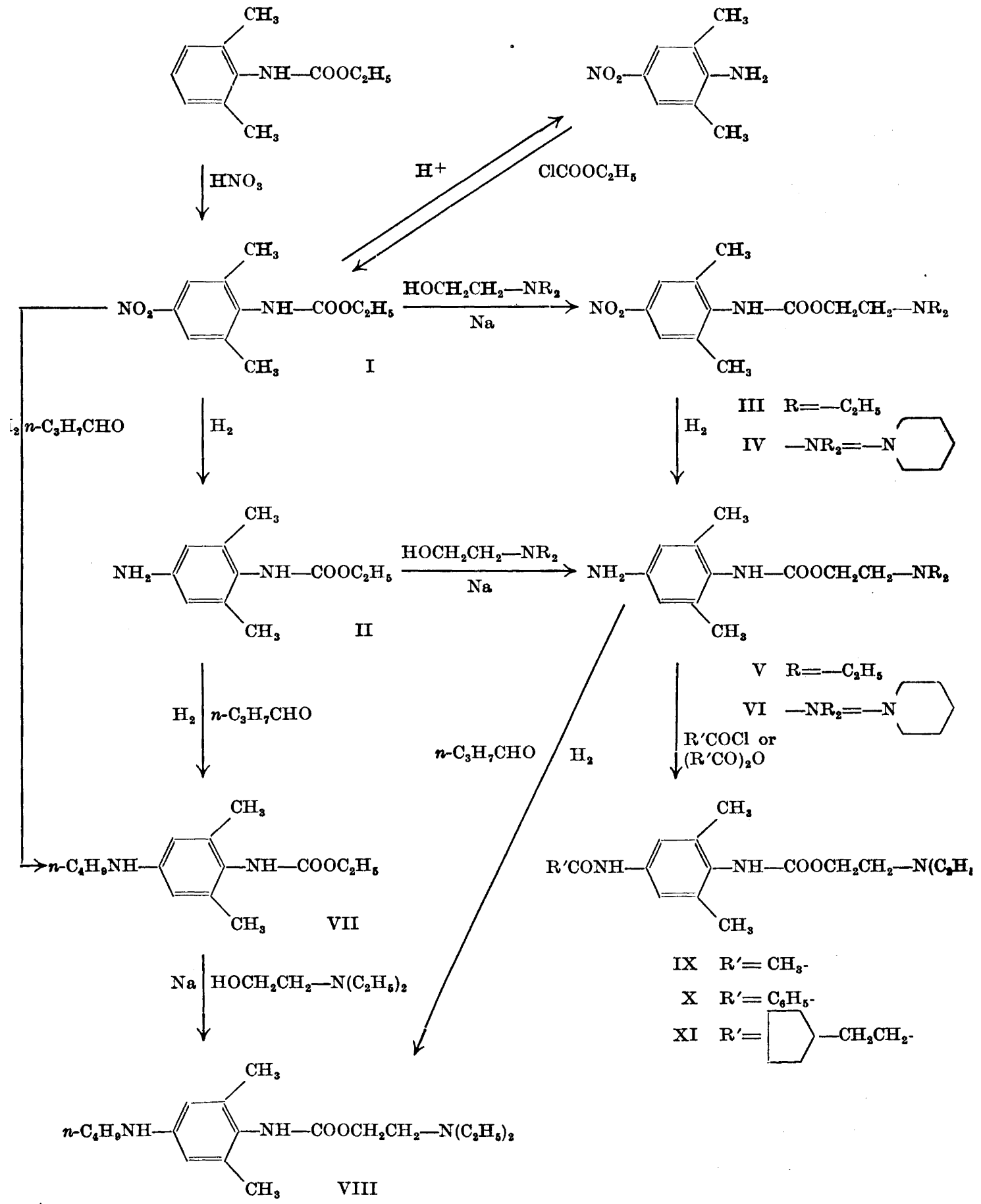

Fig. 1. 
The new compounds were tested for local anesthetic action on the rabbit cornea and compared with Xylocaine*. The $p$-amino derivatives $V$ and VI were devoid of anesthetic activity. The $n$-butylamino derivate VIII had an effect comparable with that of Xylocaine but had a longer latency time, low frequency of anesthesia and more than twice the toxicity. The acyl derivate IX was inactive, and $\mathrm{X}$ was only slightly active but XI had a strong anesthetic effect. It was, however, irritating to the rabbit eye and had a long latency time and a low frequency of anesthesia. Strong activity was also displayed by the amino esters of 2-chloro-6-methylphenylcarbamic acid (XIII, XIV), but they were too toxic to be of any clinical value.

\section{EXPERIMENTAL}

Ethyl 2,6-dimethyl-4-nitrophenylcarbamate (I). (a) 2,6-Dimethyl-4-nitroaniline (8.3 g, .0 .05 mole), prepared by hydrolysis of 2,6-dimethyl-4-nitro-1-( $p$-toluenesulfonyl)-aniline according to the method cf Wepster ${ }^{2}$, and pyridine ( $5.15 \mathrm{~g}, 0.065 \mathrm{~mole}$ ) were dissolved in benzene $(600 \mathrm{ml})$ and ethyl chloroformate $(7.0 \mathrm{~g}, 0.065 \mathrm{~mole})$ was added dropwise with mechanical stirring. The mixture was refluxed for $2.5 \mathrm{~h}$ and then filtered hot. The benzene was evaporated and the residue dissolved in ether $(800 \mathrm{ml})$ and extracted with conc. hydrochloric acid $(150+100 \mathrm{ml})$ in order to remove unreacted starting material. The ether solution was washed with water, dried over sodium sulphate and the solvent was then evaporated. The crystalline residue $(6.9 \mathrm{~g}, 58 \%)$ melted at $165-168^{\circ}$; recrystallisation from ethanol yielded pale yellow crystals of m.p. 172-173 . (Found: C 55.3; H 5.95; $\mathrm{N}$ 11.8. Calc. for $\mathrm{C}_{11} \mathrm{H}_{14} \mathrm{~N}_{2} \mathrm{O}_{4}: \mathrm{C} 55.45 ; \mathrm{H} 5.92 ; \mathrm{N} 11.8$ ).

(b) To a solution of nitric acid ( $76 \mathrm{ml}, 2$ moles; $d$ 1.50) in water $(600 \mathrm{ml}$ ) were added successively ethyl 2,6-dimethylphenylcarbamate ${ }^{1}(58 \mathrm{~g}, 0.3 \mathrm{~mole})$, glacial acetic acid $(600 \mathrm{ml})$ and sodium nitrite $(2.1 \mathrm{~g}, 0.03 \mathrm{~mole})$. The mixture was refluxed for' $1.5 \mathrm{~h}$ and after cooling to room temperature it was poured into water $(1.2 \mathrm{l})$. The crude nitro compound ( $56 \mathrm{~g}, 78 \%$ ) of m.p. $169-171^{\circ}$ was recrystallised from ethanol giving yellow crystals melting at $172-173^{\circ}$. A mixed m.p. with the product prepared by procedure $(a)$ showed no depression.

Hydrolysis of ethyl 2,6-dimethyl-4-nitrophenylcarbamate (I) to 2,6-dimethyl-4-nitroaniline. A mixture of compound I $(2.4 \mathrm{~g}, 0.01 \mathrm{~mole})$ and $85 \%$ sulphuric acid $(25 \mathrm{ml})$ was heated in an oil bath at 140-150. Evolution of carbon dioxide began at once and had subsided after $45 \mathrm{~min}$. The reaction mixture was then poured into ice water $(200 \mathrm{ml})$ and made alkaline with $5 \mathrm{~N}$ sodium hydroxide. The light yellow product (1.55 g, $94 \%)$ melted at $163-164^{\circ}$ alone or in admixture with a sample of 2,6-dimethyl-4-nitroaniline prepared according to the method of Wepster ${ }^{2}$. Recrystallisation from aqueous ethanol did not raise the m.p.

Ethyl 4-amino-2,6-dimethylphenylcarbamate (II). Ethyl 2,6-dimethyl-4-nitrophenylcarbamate $(14.3 \mathrm{~g})$, dissolved in ethanol $(125 \mathrm{ml})$, was hydrogenated at about $50^{\circ}$ and normal pressure with Raney nickel as catalyst. The calculated amount of hydrogen was consumed after $4 \mathrm{~h}$. The solution was filtered and the solvent evaporated. The crystalline residue $(12.5 \mathrm{~g}, 100 \%$ ) was recrystallised from benzene giving a product $(10.0 \mathrm{~g})$ of m.p. 107-108 . (Found: $\mathrm{C} 63.9 ; \mathrm{H} \mathrm{8.01;} \mathrm{N} \mathrm{13.1.} \mathrm{Calc.} \mathrm{for} \mathrm{C}_{11} \mathrm{H}_{16} \mathrm{~N}_{2} \mathrm{O}_{2}$ : C 63.4; $\mathrm{H} 7.74 ; \mathrm{N} 13.4$ ).

$\beta$-Diethylaminoethyl 2,6-dimethyl-4-nitrophenylcarbamate (III). A mixture of ethyl 2,6-dimethyl-4-nitrophenylcarbamate $(71.4 \mathrm{~g}, 0.3 \mathrm{~mole})$ and $\beta$-diethylaminoethanol (195 $\mathrm{g}$, $1.65 \mathrm{~mole}$ ) in which a piece of sodium (1.5 g) had been dissolved was heated at $75-80^{\circ}$ for $3 \mathrm{~h}$ at a pressure of $80-100 \mathrm{~mm} / \mathrm{Hg}$. The excess of the amino alcohol was evaporated off and the residue washed with water and extracted with $2 \mathrm{~N}$ hydrochloric acid. The acid solution was extracted with ether and made alkaline with dilute sodium hydroxide. The precipitated, semisolid base was extracted with ether. Evaporation of the ether yielded a crystalline residue $(75.0 \mathrm{~g}, 81 \%)$ of m.p. $46-48^{\circ}$. Since further purification of the base proved to be difficult, it was converted to the hydrochloride which was recrystallised

\footnotetext{
* Acknowledgement is made to Dr. S. Wiedling for performing these tests.
} 
from ethanol-ether; m.p. 164-165․ (Found: C 51.9; H 6.94; Cl 10.4. Calc. for $\mathrm{C}_{15} \mathrm{H}_{34} \mathrm{ClN}_{3} \mathrm{O}_{1}$ : C 52.1; $\left.\mathrm{H} 6.99 ; \mathrm{Cl} 10.25\right)$.

$\beta$-Piperidinoethyl 2,6.dimethyl-4-nitrophenylcarbamate (IV). This compound was prepared in $90 \%$ yield from ethyl 2,6-dimethyl-4-nitrophenylcarbamate and $\beta$-piperidinoethanol by the same method as that described for III. The amino ester base was recrystallised from methanol-water; m.p. 139-140 . (Found: C 60.0; H 7.52; N 12.7. Calc. for $\mathrm{C}_{18} \mathrm{H}_{33} \mathrm{~N}_{3} \mathrm{O}_{1}$ : C 59.8; $\mathrm{H} 7.21 ; \mathrm{N} 13.1$ ).

$\beta$-Diethylaminoethyl 4-amino-2,6-dimethylphenylcarbamate (V). (a) The nitro com. pound III $(4.2 \mathrm{~g})$ was dissolved in ethanol $(50 \mathrm{ml})$ and hydrogenated at a jout $50^{\circ}$ and normal pressure with Raney nickel as catalyst. The calculated amount of hydrogen was consumed in $2 \mathrm{~h}$. The catalyst was removed by filtration and the solvent evaporated. The colourless oily residue $(3.6 \mathrm{~g}, 95 \%)$ was converted to the dihydrochloride; m.p. $299-$ $301^{\circ}$ after recrystallisation from ethanol-ether. (Found: $\mathrm{C} \mathrm{51.3;} \mathrm{H} \mathrm{7.85;} \mathrm{Cl} \mathrm{20.4.} \mathrm{Calc.}$ for $\mathrm{C}_{15} \mathrm{H}_{3}, \mathrm{Cl}_{2} \mathrm{~N}_{3} \mathrm{O}_{2}$ : C 51.1; $\mathrm{H} 7.72 ; \mathrm{Cl} 20.1$ ).

(b) Transesterification of ethyl 4-amino-2,6-dimethylphenylcarbamate with diethylaminoethanol as described for III yielded the dihydrochloride of $\mathrm{V}$ in $50 \%$ yield. M.p. after recrystallisation from ethanol-ether $300-302^{3}$.

B-Piperidinoethyl 4-amino-2,6-dimethylphenylcarbamate (VI). The nitro compound IV was hydrogenated as described above for $V(a)$ and the piperidino ester was isolated as the dihydrochloride in $80 \%$ yield. M.p. $291-293^{\circ}$ (decomp.) after recrystallisation from ethanol-ether. (Found: $\mathrm{C}$ 52.55; $\mathrm{H}$ 7.54; $\mathrm{N}$ 11.3. Calc. for $\mathrm{C}_{16} \mathrm{H}_{27} \mathrm{Cl}_{2} \mathrm{~N}_{3} \mathrm{O}_{2}$ : $\mathrm{C}$ 52.7; $\mathrm{H}$ 7.47; N 11.5).

Ethyl 4-n-butylamino-2,6,dimethylphenylcarbamate (VII). (a) A solution of ethyl 4-amino-2,6-dimethylphenylcarbamate $(4.15 \mathrm{~g}, 0.02 \mathrm{~mole}), n$-butyraldehyde $(0.04 \mathrm{~mole})$ and fused sodium acetate $(1 \mathrm{~g})$ in ethanol $(50 \mathrm{ml})$ was hyd ogenated with Raney nickel as catalyst at normal pressure and room temperature for one hour. The catalyst was removed by filtration and the solvent evaporated. The residue was dissolved in $2 \mathrm{~N}$ hydrochloric acid, the acid solution was extracted with ether and then made alkaline with dil. sodium hydroxide. The precipitate was extracted with et 10 r and the solvent was evaporated yielding a crystalline residue $(4.7 \mathrm{~g}, 90 \%)$ of m.p. $73-74^{\circ}$. Recrystallisation from aqueous methanol raised the m.p. to $76-77^{\circ}$. (Found: $\mathrm{C} 68.15 ; \mathrm{H} 9.01 ; \mathrm{N} 10.5$. Calc. for $\mathrm{C}_{15} \mathrm{H}_{3,} \mathrm{~N}_{3} \mathrm{O}_{3}: \mathrm{C}$ 68.15; $\mathrm{H} \mathrm{9.15;} \mathrm{N} 10.6$ ).

(b) This compound could also be prepared in $82 \%$ yield by using ethyl 2,6-dimethyl4-nitrophenylcarbamate (I) as starting material in the reductive alkylation described above $(a)$. The reaction was, however, rather sluggish; the calculated amount of hydrogen was consumed after $6 \mathrm{~h}$.

B-Diethylaminosthyl 4-n-butylamino-2,6-dimsthylphenylcarbamate (VIII). (a) A solution of $\beta$-diethylaminoethyl 4-amino-2,6-dimsthylphenylearb3m ste ( $3.9 \mathrm{~g}, 0.014 \mathrm{~mole})$, $n$-butyraldehyde $(1.3 \mathrm{~g}, 0.018 \mathrm{~mole})$ and sodium acetate $(1.0 \mathrm{~g})$ in ethanol $(50 \mathrm{ml})$ was hydrogenated at normal pressure and room temperature over $R$ mey nickel for one hour. The reaction mixture was worked up as described above for compound VII (a). The pro. duct was isolated as the dihydrochloride ( $3.6 \mathrm{~g}, 62 \%)$ m.p. $236-237^{\circ}$ (decomp.) after recrystallisation from ethanol-ether. (Found: $\mathrm{C}$ 55.6; $\mathrm{H}$ 8.72; $\mathrm{N}$ 9.93. Calc. for $\mathrm{C}_{19} \mathrm{H}_{35} \mathrm{Cl}_{2} \mathrm{~N}_{3} \mathrm{O}_{2}: \mathrm{C} 55.9 ; \mathrm{H} \mathrm{8.64;} \mathrm{N} 10.3$ ).

(b) This compound was also obtaine 1 by transesterification of ethyl 4-n-butylamino2,6-dimethylphenylcarbamate with $\beta$-diethylaminoethanol according to the procedure described for compound III. The yield of the dihydrochloride was $63 \%$.

$\beta$-Diethylaminoethyl 4-acetamido-2,6-dimsthylphenylcarbamate (IX). A suspension of compound V (2.8 $\mathrm{g}$ free b3se, $0.01 \mathrm{~m}$ le $)$ in acetic anhydride $(10 \mathrm{ml}) \mathrm{was}$ he3ted to $60^{\circ}$ for $30 \mathrm{~min}$ and was then poured into water $(100 \mathrm{ml})$. The mixture was made alkaline and extracted with ether. The ether solution $w_{3}$; filtered through a short column of aluminium oxide and evaporated. The solid residue $(1.7 \mathrm{~g}, 53 \%)$ was recrystallised from benzene; m.p. $122-123^{\circ}$. (Found: $\mathrm{C} \mathrm{63.0;} \mathrm{H} \mathrm{8.45;} \mathrm{N}$ 13.1. Calc. for $\mathrm{C}_{17} \mathrm{H}_{27} \mathrm{~N}_{3} \mathrm{O}_{3}$ : $\mathrm{C} 63.5$; $\mathrm{H} 8.47 ; \mathrm{N} 13.1$ ).

$\beta$-Diethylaminothyl 4-benzamido-2,6-dimsthylplenylcarbamate $(X)$. Compound V was treated with benzoyl chloride in pyridine-benzene. A he3vy precipitate consisting of the hydrochloride of X was formod. The salt w3s suspended in water, the suspension made alkaline and the bsse extracted with ether. Evaporation of the ether yielded a crystalline residue which was recrystallised from benzene; m.p. 144-145 ${ }^{\circ}$. (Found: 69.4; $\mathrm{H}$ 7.65; $\mathrm{N}$ 10.8. Calc. for $\mathrm{C}_{22} \mathrm{H}_{29} \mathrm{~N}_{3} \mathrm{O}_{3}: \mathrm{C} 68.9 ; \mathrm{H} 7.62 ; \mathrm{N} 11.0$ ).

Acta Chem. Scand. 11 (1957) No. 8 


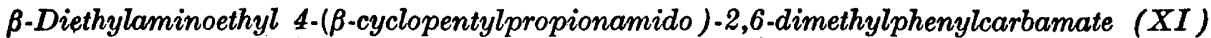
was prepared similarly in $71 \%$ yield from $V$ and $\beta$-cyclopentylpropionyl chloride; m.p. $115-116^{\circ}$ after recrystallisation from benzene-light petroleum. (Found: C 68.4; H 9.19; $\mathrm{N}$ 10.45. Calc. for $\left.\mathrm{C}_{23} \mathrm{H}_{37} \mathrm{~N}_{3} \mathrm{O}_{3}: \mathrm{C} 68.45 ; \mathrm{H} \mathrm{9.24;} \mathrm{N} 10.4\right)$.

Ethyl 2-chloro-6-methylphenylcarbamate (XII). To a stirred solution of 2-chloro-6methylaniline $(28.3 \mathrm{~g}, 0.2 \mathrm{~mole})$ and pyridine $(20 \mathrm{~g}, 0.25 \mathrm{~mole})$ in benzene $(200 \mathrm{ml})$, ethyl chloroformate $(27.1 \mathrm{~g}, 0.25 \mathrm{~mole})$ was added dropwise over a period of one hour. The temperature gradually rose to $45^{\circ}$. The stirring was then continued for one hour and the pyridine hydrochloride formed was removed by filtration. The benzene solution was washed successively with water, $2 \mathrm{~N}$ hydrochloric acid and water and was then evaporated to dryness. The residue $(38.5 \mathrm{~g}, 90 \%)$ melted at $75-77^{\circ}$ and was recrystallised from aqueous methanol; m.p. $76-77^{\circ}$. (Found: $\mathrm{C} 56.3 ; \mathrm{H} 5.69 ; \mathrm{N} 6.62$. Calc. for $\mathrm{C}_{10} \mathrm{H}_{12} \mathrm{ClNO}_{2}$ : C 56.2; H 5.66; N 6.56).

$\beta$-Diethylaminoethyl 2-chloro-6-methylphenylcarbamate (XIII). This compound was prepared by transesterification of the ethyl ester XII with $\beta$-diethylaminoethanol by the method described for compound III. The oily base was converted to the oxalate. Yield $51 \%$; m.p. 127-128 after recrystallisation from $80 \%$ ethanol. (Found: C 51.7; H 6.51; $\mathrm{N}$ 7.35. Cale. for $\mathrm{C}_{16} \mathrm{H}_{23} \mathrm{ClN}_{2} \mathrm{O}_{2}$ : C 51.3; $\mathrm{H} \mathrm{6.18;} \mathrm{N} 7.48$ ).

$\beta$-Piperidinoethyl 2-chloro-6-methylphenylcarbamate (XIV) was prepared similarly from $\beta$-piperidinoethanol and XII. The oily base was isolated as the hydrochloride. Yield $87 \%$; m.p. 172 $-173^{\circ}$ after recrystallisation from ethanol-ether. (Found: C 54.1; H 6.47; N 8.39: Calc. for $\mathrm{C}_{15} \mathrm{H}_{28} \mathrm{Cl}_{2} \mathrm{~N}_{2} \mathrm{O}_{2}: \mathrm{C} 54.05 ; \mathrm{H} 6.66 ; \mathrm{N} \mathrm{8.41)}$.

\section{REFERENCES}

1. Dahlbom, R. and Osterberg, L.-E. Acta Chem. Scand. 9 (1955) 1553.

2. Wepster, B. M. Rec. trav. chim. 73 (1954) 809.

Received May 20, 1957.

Acta Chem. Scand. 11 (1957) No. 8 